\title{
Exploring Curriculum Delivery: An Ethnographic Study of Teachers' Working Satisfaction through the Curriculum Reform Process
}

\author{
Dr. Tommi Eranpalo, Dr. Eija Valanne and Cynthia Jorgenson, ABD \\ Abu Dhabi Department of Education and Knowledge \\ Abu Dhabi, UAE
}

(This study was conducted under protection of Abu Dhabi Department of Education and Knowledge Research Office and Professor Masood Badri.)

\begin{abstract}
The article brings perspective to teachers' individual feelings and thoughts while a major curriculum reform in Abu Dhabi public schools is taking place. The aim is to identify specific curricular conditions and curriculum delivery models affecting the school community, students' learning, teachers' work satisfaction, and school culture as a whole. In the study, teachers reflect on their adaptations and emotions for the new curriculum and the changes occurring in schools. This ethnographic action study took place in four schools following 12 teachers' reflections during two school trimesters with weekly journals. The results reveal the positive pursuit of teachers to achieve expected results and adapt to the new curriculum. Results indicate that collaborative planning and stronger autonomy in the pacing of outcomes could be the key to an even more plentiful school culture in Abu Dhabi schools.
\end{abstract}

Keywords: curriculum revision; school culture; cross-cultural daptation; adaptation to change.

\section{Curriculum Revision}

The Ministry of Education (MoE) teamed up with the Abu Dhabi Department of Education and Knowledge (ADEK) to announce a major reform in education for the United Arab Emirates (UAE) at the beginning of the 2017-2018 academic school year. The announcement occurred during the professional development week, just before the school start, changing the curriculum that ADEK schools would follow to the same one followed by MoE schools. This new curriculum is the "Emirati School Model" with the goal of improving standards and 
producing better results in students' achievement (Ministry of Education, UAE, 2018).

President Sheikh Khalifa, Sheikh Mohammed bin Rashid, Vice President and Ruler of Dubai and Sheikh Mohammed bin Zayed, Crown Prince of Abu Dhabi and Deputy Supreme Commander of the Armed Forces embrace a vision to create a standardized education system for the entire country to follow in all schools. According to the MOE, a unified curriculum was essential to achieve a well-informed, supportive education system capable of change to keep up with other nations. The prime goal was to enable all schools across the country to operate within the same framework to generating graduates with the ability to meet international standards and meet aspirations and expectations of the UAE people (MOE, 2018).

The new curriculum was delivered as a "first-rate education system" aligned to the UAE Vision 2021. The public schools had been mandated to incorporate more Science and Math into the curriculum to better prepare students for the future. According to MoE, the Emirati School Model was set to play a major role in standardizing education for all seven emirates.

The curriculum within the Emirati School Model has a spiral design; new information taught is delivered based on previous learning. Moving to a spiral curriculum instead of linear helps boost teacher confidence in the teaching process and allow meta-cognitive monitoring to control the learning. The development of meta-cognitive strategies helps individuals to improve their learning effectiveness and increase motivation towards schoolwork. By developing students' meta-cognitive learning capacities, educators can make way for better results in learning and chart student achievement based on the desired outcomes (Jorgenson, Eranpalo, Deria \& Kumar, 2017). This system transformation will be a major effort for schools and have significant impact for the education of all students in the UAE.

Research recently provided information to show that effective change happens when curricula needs of teachers as well as students are addressed throughout the organization (Ball \& Cohen, 1996; Davis \& Krajcik, 2005). An understanding of how teachers, particularly experienced teachers, use Emirati School Model curriculum to modify their teaching practices leads to the promotion of change on a large-scale in the teaching-learning process. However, presenting teachers with new ideas and curriculum materials does not necessarily promote change in instructional practices. Change only occurs when teachers interact with materials and relevant pedagogical concepts while actually working with students (Remillard \& Bryans, 2004).

The involvement of all stakeholders, especially individuals directly involved in student instruction, is especially vital part in the success of curriculum reform. Without acceptance and buy-in from all involved, systemic change won't occur and continue over time (Johnson, 2018).Curriculum reformers around the world believe students play a critical role in their own learning, with teachers being 
crucial to the adaptations and implementation of the curriculum. The interaction of teachers and learners with the curriculum content is as important as the content itself (Drake \& Sherin, 2006). Johnson (2018) focused on the need for teacher ownership in the revision process. The effectiveness rate was considerably higher when teachers who used the curriculum were directly involved in reviewing, rewriting, and revising the program. Furthermore, Sahlberg (2012) understood that curriculum needed to be school-based because prescribing system-level policies made more sense when put into action within prospective schools. Values, purpose, and goals of a school are more valuable when teachers and administration tailor them using their professional judgment and input from stakeholders.

New curriculum always brings major change into schools. Therefore, change management plays an important role in curriculum revision. Hargreaves (1997) gave a summation on why reforms may fail in schools. He stated that educational changes fail because:

- The change is poorly conceptualized or not clearly demonstrated.

- The change is too broad and ambitious so that teachers have to work on too many fronts or it is too limited and specific so that little real change occurs at all.

- The change is too fast for people to cope with, or too slow so that they become impatient or bored and move on to something else.

- The change is poorly resourced or resources are withdrawn once the first flush of innovation is over. There is not enough money for materials or time for teachers to plan.

- There is no long-term commitment to the change to carry people through the anxiety, frustration, and despair of early experimentation and unavoidable setbacks. (p. 68)

Since the current educational climate shows rapid growth of autonomous schools while continuing to hold schools accountable for student attainment, promoting a research-based, engaging curriculum review would benefit any school. Educational institutes are considered learning organizations and developing a culture of professional engagement would lead to long-term, sustainable improvement (Godfrey, 2014).

As an example of a research based school improvement project, the journey of several public schools in Abu Dhabi in the Collaborative Curriculum Delivery Pilot ${ }^{1}$ culminates with this ethnographic study. The project proceeded in stages

\footnotetext{
${ }^{1}$ Articles in the Collaborative Curriculum Delivery Pilot include the following:

- $\quad$ Eranpalo, T., Jorgenson C. K. \& Woolsey, M. L. 2016. The Abu Dhabi school model: Effective delivery of the curriculum. International Journal of Humanities and Social Sciences Vol 8, No 6

- Jorgenson, C. A., Eranpalo, T., Deria, A.M. \& Kumar R. 2017. Using Abu Dhabi Education Council's Abu Dhabi School Model Outcomes to Reorganize Curriculum from Linear Delivery toward a Spiral Approach. International Journal of Humanities and Social Sciences Vol 9, No 3
} 
with one stage's ending providing a starting point for the next stage. The schools within the projects have had the privilege to make their own contribution to the curriculum reform. This final article of the series focuses on the effects curriculum reform has on school communities and culture.

\section{School Culture}

Even though school culture is of high importance when a school goes through structural changes, most people neglect this element. Schein (1985) sees the basis of an organization's culture to be: "the deeper level of basic assumptions and beliefs that are shared by members of an organization, that operate unconsciously, and that define in a basic 'taken-for-granted' fashion an organization's view of itself and its environment" (p. 6-7). Change becomes hard to grasp when school culture is built around these concepts. Macneil, Prater and Bush (2009) remind us of the complexity of school culture based on the several specific idiosyncrasies within it. School cultures have shared orientations, values, practices and norms holding it together. These give each school a distinct identity making it somewhat resistant to outside change (Kaplan \& Owings, 2013). The belief is that for a school to change, the culture needs to be overhauled. The process for this makes things that are unclear understood. In a climate built on mutual respect, trust, honesty and openness, stakeholders can take a closer look at their own beliefs and behaviors, identifying the ways they add to the need for climate change.

Recent researches in this field state that manipulation of school culture is the first step towards a productive school. Authors agree that positive school culture has a powerful influence on staff engagement and that culture re-boot is crucial for any struggling school to be successful (Kaplan \& Owings, 2013). The positive concepts to boost culture include shared leadership, collaboration and collegiality. In addition, successful schools have certain features that define their identity. Butucha (2013) points out that to understand any organization begins by understanding its culture.

If the working conditions and climate is poor and school emulates a negative culture, the much appreciated values, collaboration and collegiality cannot operate, and shared leadership is absent. Researchers are highlighting many concepts for school improvement like unity of purpose, shared vision and collaborative commitment. It is presumed that the administrators of the school empower job satisfaction; however, administrators will be incapable to bring about positive change when the school culture is negative. Achieving a level of shared understanding is necessary if any new concepts are introduced to

- Valanne, E., Al Dhaheri, R., Kylmalahti, R. \& Sandholm-Rangell, H. 2017. Phenomenon Based Learning Implemented in Abu Dhabi School Model. International Journal of Humanities and Social Sciences Vol 9, No 3

- The final action research, an ethnographic field study AY 2017-2018 “Exploring curriculum delivery -An ethnographic study of teachers working satisfaction of the curriculum reform process" results published June 2018. 
teachers. Without a suitable climate for change, teachers cannot be effective change agents and a positive culture is not achievable. Positive school culture supports the professionalism among teachers to be committed to learning achievements of students. It encompasses vision and direction desired for all stakeholders (Msila, 2014.)

When looking at schools through a cultural lens, an observer sees the state of affairs in the school community. Viewing a school through this lens uncovers the reality of community members while giving identity and creating an everyday framework to support teaching and learning. Every school has its own mindset, and people who work together develop what can be expressed: "the way we do things around here" (Stoll, 1998). A healthy starting point for cultural change is to recheck the school practices, "Is this the way we want to do things around here?"

This is easy to understand, and when it comes to re-boosting the school culture during our pilot project, we grasped a rare opportunity to compare the change between different realities and mindsets. Culture inside a project also has its own mindset in relation to what occurs in its internal environment. Culture is thus, "situationally unique" (Kaplan \& Owings, 2013).

Rosenholtz (1989) has a take on schools being either "moving" or "stuck", agreeing that there are real differences in their cultures. For example, there are two schools with similar populations in the same school district, yet the school has different mindsets. The difference in these schools is the 'moving' school focuses on internal priorities to promote improvement while the 'stuck' school focuses on outside expectations to guide it. Macneil et al. (2009) studied four groups of schools and how they were affected by the change in school culture and the effect on students' achievement. They discovered that goal-focused schools and schools that are adaptable showed the greatest variance in school culture. The school administrator must develop and support systems in the school that minimize stress and maintain stability while dealing with changes in the school environment so that the community can adapt to change.

Stoll and Fink's (1996) study further delved into school culture. The focus was around school effectiveness arguing that the world around us is changing fast so schools must adapt to these changes or fail. The study has a two-dimensional focus on effectiveness-ineffectiveness, and improving-declining when discussing school culture. Of course, within any given school, researchers can find all types of

sub-cultures and levels of dimensions in the whole, this was the starting point for Gruenert and Whitaker (2015) when they described a leveling of school culture from toxic to collaborative, to juxtapose positive school culture with negative culture for clarity. 


\section{Cultural Adaptation}

The concept of cultural adaptation refers to the process a person or a group takes to assimilate to new cultural conditions. Cultural adaptation occurs across four stages in most research descriptions (see Figure 1). The initial stage is referred to as the "honeymoon stage" because individuals are still fascinated and excited with the newness of the changes. After the initial stage, disillusionment and frustration set in. This can be considered the "culture shock" stage when people in the organization begin to realize the day-to-day effects of coping with the change. As people gradually adapt to the new culture and learn what is expected, they move into the "adjustment stage". The final stage, "mastery", happens when individuals begin to understand and embrace the new culture (Lysgaard, 1955; Berry, 2006; Geeraert \& Demoulin, 2013).

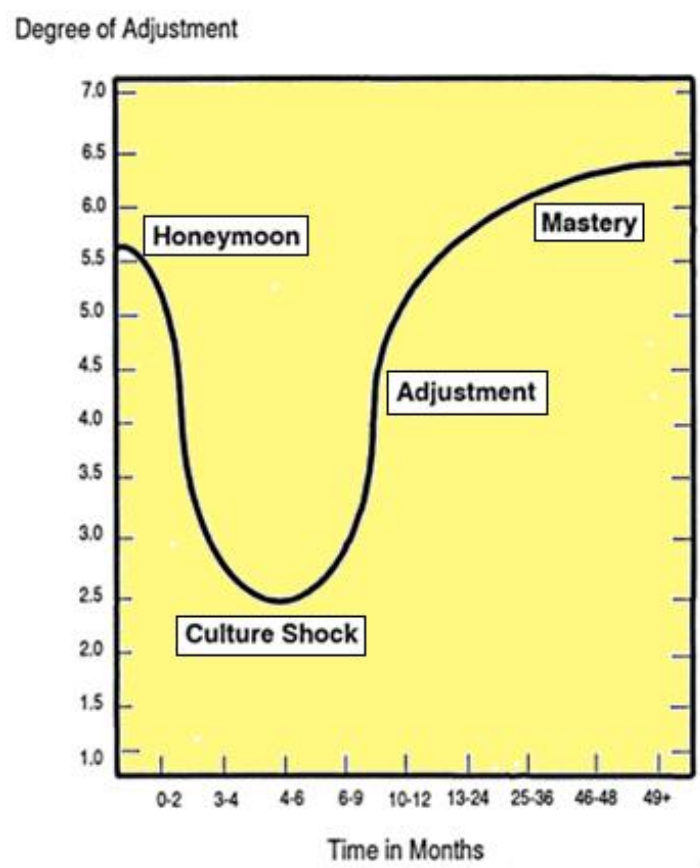

Figure 1: Degrees of adjustment

Lysgaard (1955) can be credited with beginning empirical work on cultural adaptation. He analyzed three groups of Norwegian students who had been Fulbright scholars in the United States. Students who had stayed in the U.S. sixeighteen months reported lower adjustment that those who had stayed less than six months or more than eighteen months. Since then, researchers over decades have been interested in what impact there is on the individual, when they move to a new culture (Church, 1982; Berry, 1997; Schwartz, Unger, Zamboanga, \& Szapocznik, 2010; Geeraert \& Demoulin, 2013).

At the beginning, researchers assumed that "culture shock" was something that always happened when people relocated to areas with different cultures. Oberg (1960) as well as others during that time described culture shock as a disease with symptoms such as nervousness, anger issues, and absent-mindedness. Research that is more recent shows that moving to an unfamiliar culture is not 
always negative in nature. Geeraert and Demoulin (2013) found when foreign exchange students arrive in their host country the stress levels decrease from those of pre-travel. "Acculturative stress" has become the term to use instead of culture shock to describe the impact of the culture change on a person (Berry, 1997). Acculturative stress puts focus on the phases of coping stress and adjustment instead of the negative experience (Berry, 2006). The acculturation process is recognized as a series of events that bring about a need to deal with stress. Certainly, individuals have different factors influencing stress within their own lives (Carver \& Connor-Smith, 2010; Penley \& Tomaka, 2002)and this diversity has an effect on the acculturation of an organization (Berry, 1997; Herman \& Tetrick, 2009; Ward, Leong, \& Low, 2004).

The focus of study in the field of acculturation is the "highs and lows" of adaptation on those involved (Berry, 1997; Ward et al., 2001). What is causing stress, what accounts for the adjustment over time and what end up the consequences are where the questions are centered (Geeraert \& Demoulin, 2013; Demes \& Geeraert, 2015).Researchers are perplexed by what variables lower or heighten acculturative stress. An example could be perceived discrimination impact. There is a possibility that experiencing discrimination can add to the acculturative stress by making the individual believe that peace of mind is unreachable and the noxious stimulus is negatively affecting the coping skills. Acculturative stress is a complex psychocultural phenomenon, which provides an explanation for an individual to adapt to new cultures, and the stresses associated to change.

\section{Satisfaction and adaptation to change}

The cultural change we are studying in this project is the new curriculum for Abu Dhabi schools and systems for pacing the teaching, exams and grading. It is clear that major changes in curricular conditions will cause reactions, and how teachers adapt to the new situation is in our interest. While studying adaptation, Brickman and Campbell (1971) delivered the original hedonic adaptation theory in their essay "Hedonic Relativism and Planning the Good Society". The hedonic adaptation theory is one way of viewing cultural changes in an organization. This theory shows how quickly people return to a stable satisfaction level even though there have been major life changes. The hedonic adaptation theory asserts that when someone reaches higher expectations, both expectations and desires increase together resulting in no permanent gain in satisfaction.

In the 1990s, Michael Eysenck modified the concept and renamed it "hedonic treadmill theory" comparing a person's pursuit for happiness to that of a person on a treadmill, you must keep walking to stay in one place. According to Brickman and Campbell (1971) people initially react to positive and negative life events, but return to normal quickly. So whether someone is happy or unhappy is merely a short-term reaction to changes in life. People constantly pursue accomplishments professionally, new social relationships or solutions to problems in their quest for satisfaction. People are naturally looking for new higher goals, to strive for satisfaction only to realize that the pursuit will not relatively increase their satisfaction in the end. 


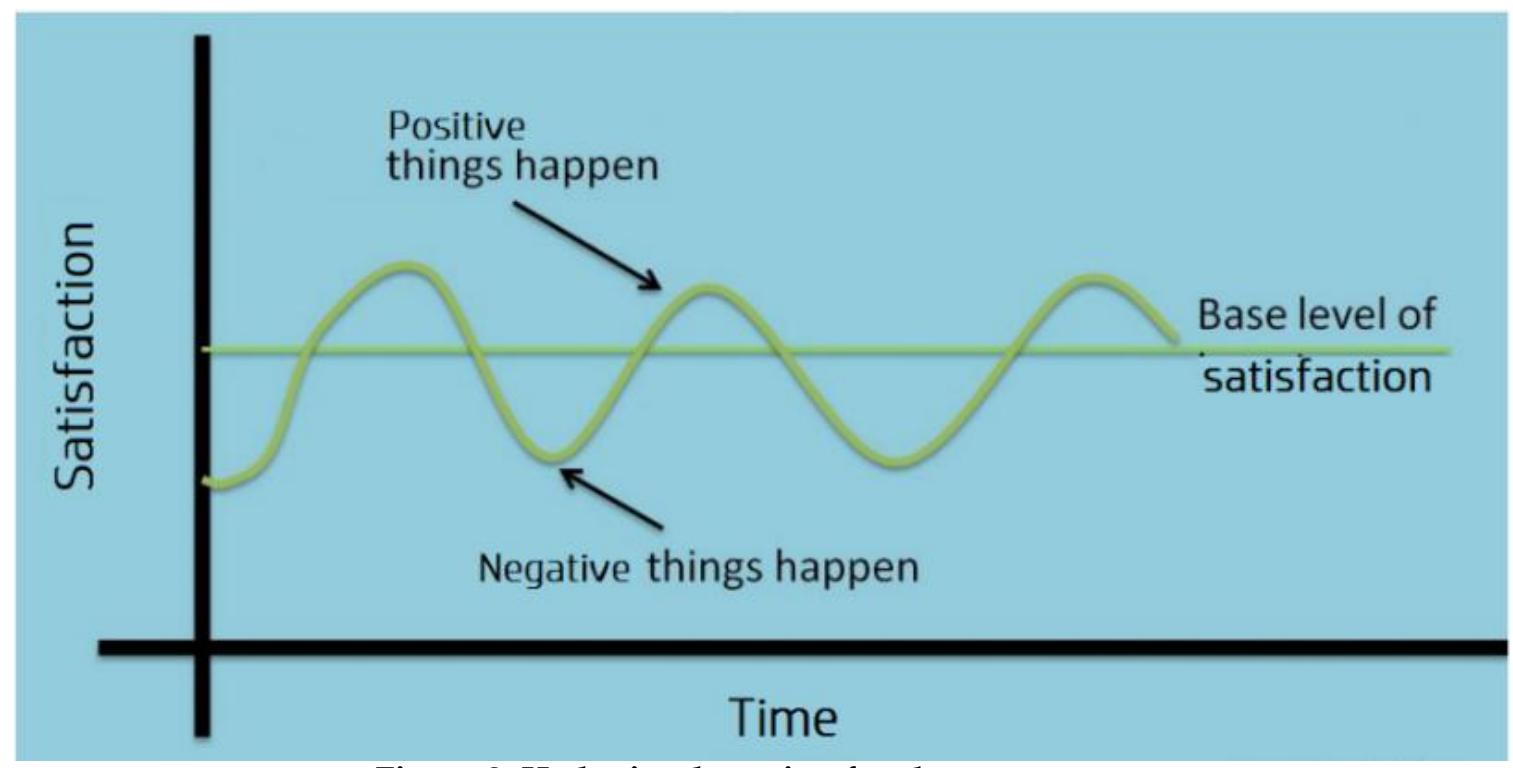

Figure 2: Hedonic adaptation for change

People normally experience satisfaction even in the middle of transitions, but having a deeper understanding of individual ways to cope with changes, informs us to when and why adaptation occurs or not. For example, in our study the starting point for adaptation is different, depending on each person's disposition toward the new curricula.

There are two research trends dealing with people's ability to adapt to events they think of as negative. The first trend focuses on specific coping strategies being utilized. The second focuses on characteristics in people's personalities that have an effect on coping skills used. When studying this information, it is evident that individuals use differing strategies and some coping strategies are more effective than others are. Furthermore, the effectiveness of strategies varies among individuals (Diener, Lucas \&Scollon, 2006). For example, people using strategies to reevaluate experiences show more positive emotions than individuals who suppress their emotions (Gross \& John, 2003). Having the skills to reappraise situations is associated with better interpersonal relationships, allowing for increased social support. Staudinger and Fleeson (1996) addressed that older people enlist coping styles such as humor, looking for information and just keeping on the same track to adjust for their age and experience. Researchers specialized in personality showed us that individual differences cause people to choose different coping strategies. Dissatisfied individuals often choose strategies that will fail for coping, causing a stressful event to become worse slowing down recovery to a stable status (Bolger \& Zuckerman, 1995).

The treadmill approach to satisfaction was a true breakthrough for psychologists to understand satisfaction with longitudinal findings to support the idea. The conclusions pointed to different types of well-being changing at different rates or even taking different directions. Researchers agree that any final form of adaptation theory is indefensible. Adaptation can proceed at a slow rate for years or never come to fruition at times. In the end, there is mutual 
understanding of individual differences in the rates of adaptation (Diener, Lucas \& Scollon, 2006).

Heracleous (2001) threw forcibility into the mix. If management promotes change through a coercive system in a situation where people are capable, motivated, and business-minded, there will be major disagreement between those endorsing the change and the individuals in the organization being forced to change. This would obviously threaten the success of the change program. Through his study, he determined that behaviors, values, beliefs and assumptions are all intertwined. There can be conflict between assumptions and the new behaviors, values, and beliefs or support can arise. So to research organizational change, one must identify the overall assumptions and work to ensure the new behaviors, values, and beliefs support these assumptions instead of clash. If the assumptions that exist mesh with the new values, beliefs and behaviors, change is more likely to be successful.

How satisfied employees are makes it possible to change the entire culture of an organization when we have an understanding that organizational policies can influence. Philosophers believe that people in society need to be satisfied for them to perform at their best. Diener and Seligman (2004) developed a system to evaluate the well-being of people over time and in different situations. The idea is to measure 'subjective well-being' in the organization. This measurement is to enlighten policymakers on what makes people satisfied and dissatisfied, to use measures of subjective well-being for analyzing the 'collective well-being'. The policymakers could then develop programs to enhance satisfaction and even further use the information collected to develop policies to promote more engagement, joy, trust and affection among employees. (Diener et al., 2006.)

\section{Framework of the Study}

This ethnographic action research was designed to explore the means of collaborative curriculum planning and delivery in four government schools in Abu Dhabi. Two of the pilot schools are Cycle 1 schools with grades 1-5 (a male school and a co-ed school) and two of them Cycle 2 male schools with grades 69. Data were gathered on weekly basis from 12 individual teachers teaching grades 1-9, as well as through monthly group discussions with the researchers. The aim was to determine how this new curriculum delivery facilitates teacherstudent relationship and how it engages teachers to teaching and to the community ownership.

The objective of the study was to investigate teacher experiences while participating in a curriculum delivery in Abu Dhabi schools (C1-C2) during the first two terms of the 2017-2018 school year. Teachers reflected their feelings towards adaptation to the new MoE curriculum that inflicted changes in their professional activities and the school culture. Whenever the school culture is changed, there is a cycle of critical reflection leading to emotions, action, discussion, feedback and an upgrading of the organization (Kaplan \& Owings, 2013). These are the elements we are about to reveal. 
Ethnographic action research has been credited as being an alternative research design originating from the field of anthropology and early qualitative research models. The emphasis with this type of study is to study the entire culture of the community in question (Hearn et al., 2009). The ethnographic approach is very useful when analyzing qualitative data and identifying unstated desires among community members (Tacchi et al., 2009). In order to achieve significant positive change in a situation, it's important to create sense of ownership for all stakeholders (Tacchi et al., 2003; Spradley, 2016).

The beginning of an ethnographic study is to identify experiences of those involved in the phenomena. To achieve this, ethnographic researchers need extended time to be immersed in the setting of the research so they can understand the issues that are present within the organization prior to and during the change, using this understanding to relate to the wider picture. This consists of gathering information on participants and sharing it with them (Tacchi et al., 2003; Spradley, 2016). Ethnographic research is not statistics-based, it is the gathering of personal experiences and thoughts of participants to gain a deeper understanding (Foth, 2006) and, to identify influences and decisions underpinning pedagogy and research in the field of education (Dujardin, 2013).

Ethnography, according to some researchers, is formed from partial truths and fragments of discourse providing the reader with a window into the world being observed. Bjerrun Neilsen (1995) had a different idea for ethnographic texts, focusing on the effects the texts have on the readers. She sees writings as seductions; the author must be able to convince and persuade the study to have validity.

Validity is a question often raised up when ethnographic study is concerned, because of the subjective nature of this approach. In this case, we use the method of configurational validity ${ }^{2}$, which allows for the belief of validity being enhanced

by multiple points of view. Validity ensures that the reporting has rigor, not only to persuade or compel the reader, but also to sort and extract facts when needed. This allows researchers to layer the points of view within the study (Goldman-Segal, 1995).

We recognize the internal "strength" (validus in Latin) of a reporting, not only by its rhetorical ability to persuade, its compelling authority, and its exclusive use of canon and genre, but by its ability to bend, to be resilient, and to be reconfigured into new groupings. Research also gets validity by combining the conflicting and congenial views, providing a format for variance and diversity. Configurational validity is achieved with a "platform for multi-logging" (Goldman-Segal, 1995; Goldman-Segal, 1998). In this study, we used the method of configurational validity to collect and scope the information gathered from

\footnotetext{
${ }^{2}$ Configurational validity is a system originally generated to validate and analyze video-based documents covering more than one point of view without judgement. It relies on finding the underlying themes within the event linking the interpretations through inquiry to make valid conclusions.
} 
the teacher narratives, discussions and field notes. We compared the pinpointed (student, teacher, community) reflections to the theory of cultural adaptation. With this method, we were able to find the meaningful reasons and explanations for both "highs and lows" during the research period.

To investigate teachers' satisfaction on the curriculum reform in Abu Dhabi, we combined the taxonomy of school cultures from Stoll and Fink (1996) and Gruenert and Whitaker (2015). By doing this, a suitable scale to describe the cultural adaptation for MoE curriculum in the Pilot schools became evident.

Figure 3 represents the typology of our study. School culture can be seen as effective and improving on three levels, as well as declining and ineffective. In the middle is one more level, strolling, to describe situation where conflicting forces inhibit improvement.

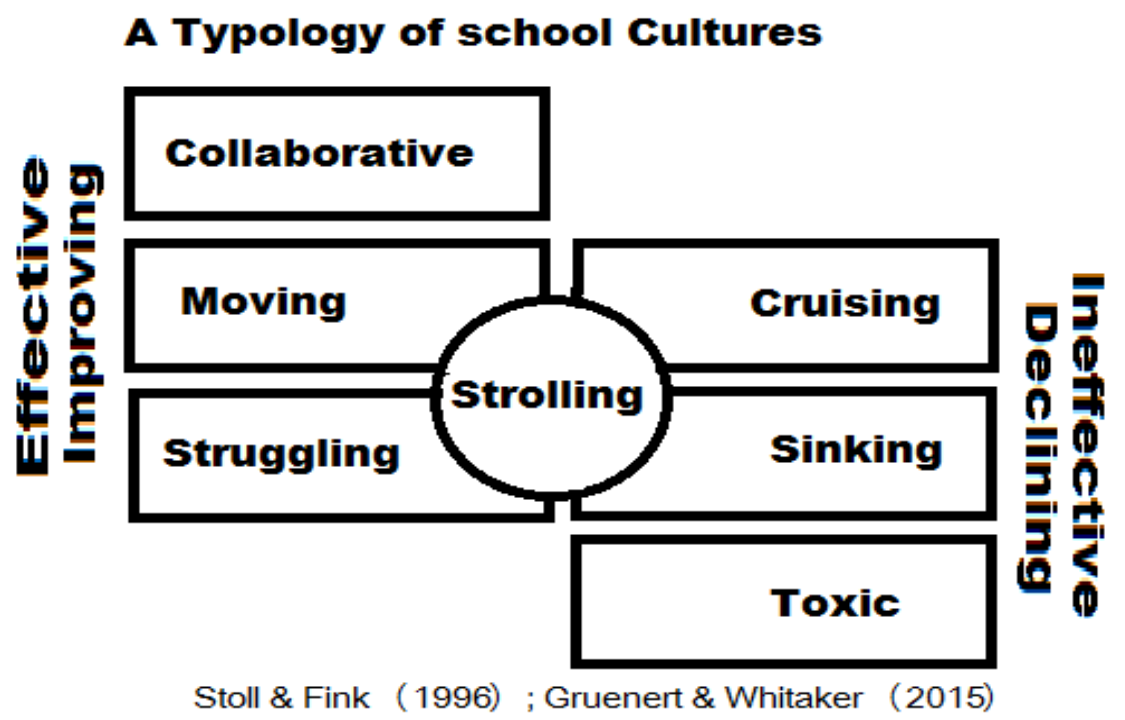

Figure 3: School culture typology

A school should become a community of collaborative learning to maximize students' achievement. The instructional leaders must strive to get teacher collegiality to increase. The opposite is also true: a toxic school culture sucks the energy out of the organization creating a situation where improvement is not an option.

As a result of this combination and incremental changes to structure, the adaptation of school culture typology was derived into school culture taxonomy presented in Chart 1. 
Chart 1: School culture taxonomy

\begin{tabular}{|c|c|c|c|c|c|c|}
\hline $\begin{array}{l}\text { Collaborative } \\
\text { School Culture }\end{array}$ & $\begin{array}{l}\text { Moving } \\
\text { School Culture }\end{array}$ & $\begin{array}{l}\text { Cruising } \\
\text { School } \\
\text { Culture } \\
\end{array}$ & $\begin{array}{l}\text { Strolling } \\
\text { School } \\
\text { Culture } \\
\end{array}$ & $\begin{array}{l}\text { Struggling } \\
\text { School } \\
\text { Culture } \\
\end{array}$ & $\begin{array}{l}\text { Sinking } \\
\text { School Culture }\end{array}$ & $\begin{array}{l}\text { Toxic } \\
\text { School Culture }\end{array}$ \\
\hline \multirow{2}{*}{$\begin{array}{l}\text { School has } \\
\text { Strong } \\
\text { educational } \\
\text { values }\end{array}$} & $\begin{array}{l}\text { Boosting pupils' } \\
\text { progress and } \\
\text { development }\end{array}$ & $\begin{array}{l}\text { We appear to } \\
\text { be effective }\end{array}$ & $\begin{array}{l}\text { Neither } \\
\text { particularly } \\
\text { effective nor } \\
\text { ineffective }\end{array}$ & $\begin{array}{l}\text { Ineffective } \\
\text { work and we } \\
\text { know it }\end{array}$ & \multirow{2}{*}{$\begin{array}{l}\text { Our work is } \\
\text { ineffective: } \\
\text { norms of } \\
\text { isolation, } \\
\text { blame, self- } \\
\text { reliance, and } \\
\text { loss of faith } \\
\text { powerfully } \\
\text { inhibit } \\
\text { improvement }\end{array}$} & \multirow{3}{*}{$\begin{array}{l}\text { Significant } \\
\text { numbers of } \\
\text { teachers focus on } \\
\text { the negative } \\
\text { aspects of the } \\
\text { school's } \\
\text { operations and } \\
\text { personnel, using } \\
\text { these flaws as } \\
\text { justification for } \\
\text { poor } \\
\text { performance. }\end{array}$} \\
\hline & $\begin{array}{l}\text { Working to } \\
\text { respond to } \\
\text { changing } \\
\text { context }\end{array}$ & $\begin{array}{l}\text { Pupils are } \\
\text { achieving in } \\
\text { spite of } \\
\text { teaching } \\
\text { quality }\end{array}$ & $\begin{array}{l}\text { Moving at } \\
\text { inadequate } \\
\text { rate to cope } \\
\text { with pace of } \\
\text { change }\end{array}$ & $\begin{array}{l}\text { We have } \\
\text { unproductive } \\
\text { structures }\end{array}$ & & \\
\hline $\begin{array}{l}\text { We are } \\
\text { improving in } \\
\text { collaboration }\end{array}$ & $\begin{array}{l}\text { Possessing } \\
\text { norms of } \\
\text { improving } \\
\text { schools }\end{array}$ & $\begin{array}{l}\text { Possessing } \\
\text { norms and } \\
\text { structures that } \\
\text { inhibit change }\end{array}$ & $\begin{array}{l}\text { Conflicting } \\
\text { aims inhibit } \\
\text { improveme } \\
\text { nt }\end{array}$ & $\begin{array}{l}\text { Often } \\
\text { identified as } \\
\text { 'failing', } \\
\text { which is } \\
\text { demotivatio- } \\
\text { nal }\end{array}$ & $\begin{array}{l}\text { School needs } \\
\text { dramatic } \\
\text { change and } \\
\text { significant } \\
\text { support }\end{array}$ & \\
\hline
\end{tabular}

\begin{tabular}{|c|c|c|c|c|c|c|c|c|c|c|c|c|c|c|c|c|c|c|c|c|c|}
\hline \multicolumn{22}{|c|}{ COLLABORATIVE CURRICULUM DELIVERY PILOT 2017-2018 } \\
\hline 40 & \begin{tabular}{|l|l}
41 \\
\end{tabular} & 42 & 43 & 44 & 45 & 46 & 47 & 48 & 49 & 50 & 2 & 3 & 4 & 5 & 6 & \begin{tabular}{|l|}
7 \\
\end{tabular} & 8 & 9 & 10 & 11 & 12 \\
\hline \multicolumn{22}{|c|}{ Weekly Notes } \\
\hline & & & & & \multicolumn{5}{|c|}{\begin{tabular}{|l|} 
Reflection \\
(comparison to previous)
\end{tabular}} & \multicolumn{6}{|c|}{$\begin{array}{l}\text { Description } \\
\text { (what is happening in the } \\
\text { classroom) }\end{array}$} & \multicolumn{6}{|c|}{$\begin{array}{l}\text { Evaluation } \\
\text { (Results of de livery) }\end{array}$} \\
\hline \multicolumn{5}{|c|}{\begin{tabular}{|l|} 
Students \\
(describe the interaction \\
and the role of the \\
learners) \\
\end{tabular}} & & & & & & & & & & & & & & & & & \\
\hline \multicolumn{5}{|c|}{\begin{tabular}{|l|} 
Teacher \\
(de scribe your own \\
feelings and intuition \\
about planning and \\
teaching)
\end{tabular}} & & & & & & & & & & & & & & & & & \\
\hline \multicolumn{5}{|c|}{$\begin{array}{l}\text { Community } \\
\text { (describe the atmosphere } \\
\text { in your working } \\
\text { communty) }\end{array}$} & & & & & & & & & & & & & & & & & \\
\hline \multicolumn{22}{|c|}{$\begin{array}{l}\text { Weekly overall: } \\
\text { Toxic }-3 / \text { Sinking }-2 \text { / Struggling }-1 / \text { Strolling } 0 / \text { Cruising }+1 / \text { Moving }+2 / \text { Collaborative }+3\end{array}$} \\
\hline
\end{tabular}

Figure 4: Teacher reflection template

The teachers were reflecting on their daily school life weekly. The reflections were collected electronically by email every Thursday. To provide some consistency to the reflection, we created a template covering three points of view: student, teacher and community. This template is presented on Figure 4 . We also guided teachers to write their ideas and feelings during the week on the template.

In addition to these reflections, teachers were also asked to rate an overall score for the week using the school culture taxonomy we combined from the studies 
of Stoll and Fink (1996) and Gruenert and Whitaker (2015). We graded our taxonomy with numeric scale from -3 (being the weakest) to +3 (as the strongest) for the analysis at a later time and to measure the "collective well-being" of the community (Diener \& Seligman, 2004).

\section{Results}

During the compilation of the reflections and results, schools' and teachers' anonymity had to be secured. This study was to address the thoughts and concerns of the teachers in midst of the curriculum reform, without any intentions to compare the schools or teachers involved. In order to prevent any community or individual from being addressed or pointed out by the results, we keep full anonymity for the stakeholders.

Through the duration of reflections, patterns became visible in the overall weekly impressions given by teachers using the school culture taxonomy. A board was created as a visual of the responses from teachers. Weekly responses were recorded on the board showing individual curves of different acculturation experiences (Geeraert \& Demoulin, 2013; Demes \& Geeraert, 2015) and strategies of adaptation (Diener, Lucas \& Scollon, 2006). Chart 2 shows the representation of the weekly overall responses received throughout the entire research period. The black line demonstrates the overall results of the teachers.

Chart 2: Teacher overall reflections

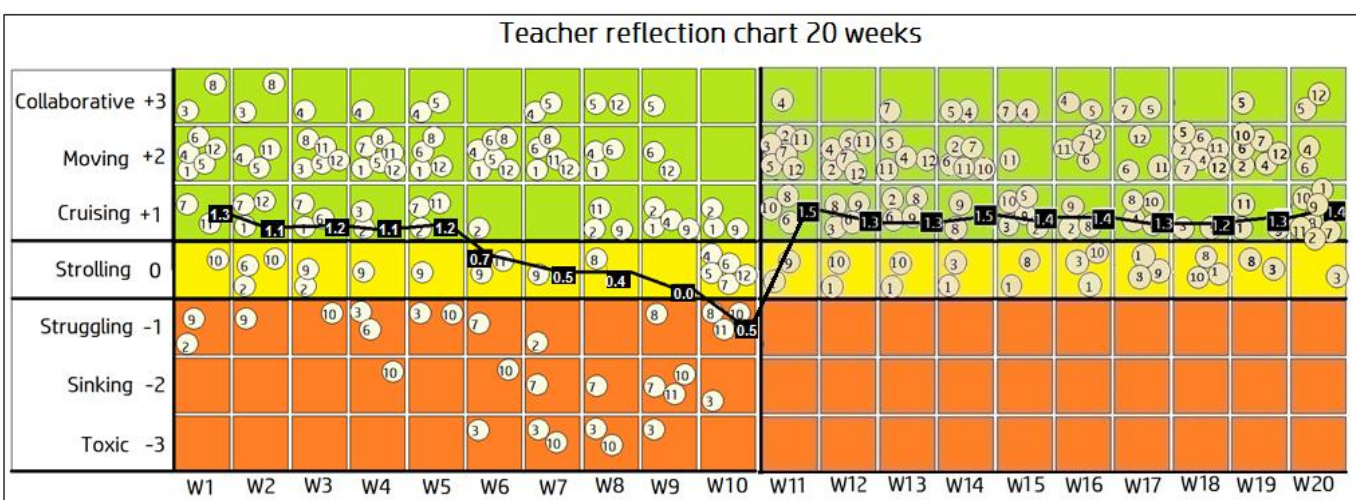

In the beginning of the study, the starting point for adaptation showed teachers having quite different attitudes towards the change. By following the teacher reflections week after week, we can see the individual curves varying strongly. In addition, if we compare the deviation of teacher scoring during the first and second term of the study, significant change occurs.

During term one, the deviation is clearly wider, which indicates that teachers had different starting points, different reactions and different methods of coping with change. Furthermore, especially weeks from six to nine are showing the overall impressions being divided into two groups; one indicating a positive school culture and the other revealing negative attitudes among teachers. Approaching the end of the first term, the deviation narrows. This collating effect continues through the second term, moving the impressions to the neutral 
and positive side of the scale. This vertical movement on the scale embodies both adaptation for the new curriculum and the positive pursuit of teachers to achieve good results in their work.

When we delve farther into the weekly average score of overall teacher impressions in search of collective well-being of the community (Diener \& Seligman, 2004), there are clear culminations points over time. These culmination points show an evident relationship to school every day life and important academic changes in the school year impacted by the new curricula.

\section{Chart 3. Reflection average}

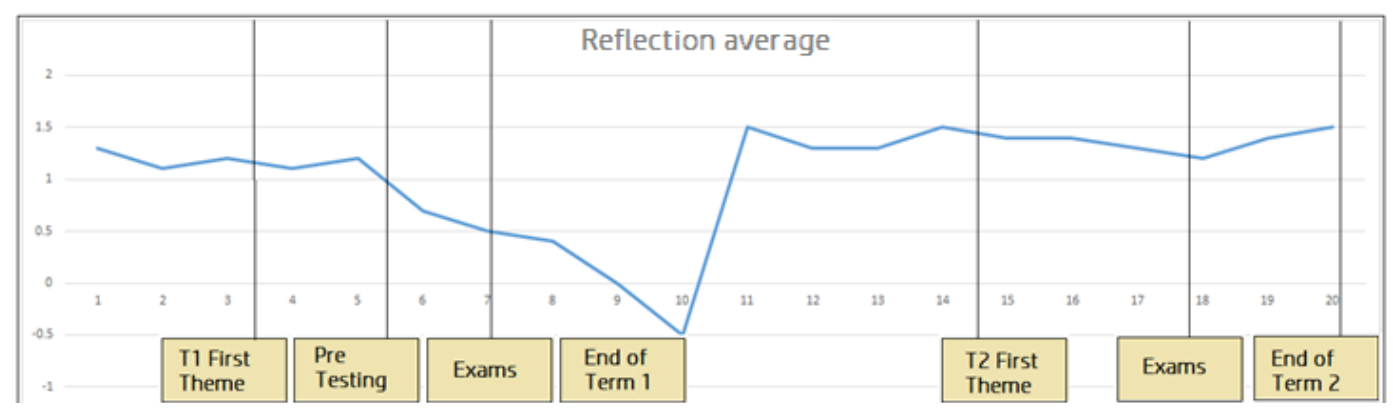

Chart 3 shows the change in school culture based on the academic calendar for the period studied.

By focusing on the progress of the whole group, we get a clear picture of the phenomenon. We can see, that the curve of reflection average (weekly average of 12 teacher scores) from our study resembles the traditional cultural adaptation curve (Lysgaard, 1955), with "culture shock" being generally preferred rift of acculturative stress. In the wording of our school culture taxonomy, the first term started showing the culture as "cruising" followed by a decline to "strolling", with a further drop be week 10 to a "struggling" school culture.

The second term was mirroring "Cruising" school culture throughout the whole 10 weeks. This can be further equated with the hedonic treadmill theory (Eysenck, 1990).

By following the overall scoring and collective well-being of teachers through the cultural change, we can say that even though individual experiences varied strongly, collectively the weekly average shows the adaptation to the change of curriculum is following the traditional pattern of cultural adaptation and reflecting hedonic treadmill. To describe the standard of school culture we can state that we are "Cruising" meaning: We appear to be effective. Pupils are achieving in spite of teaching quality and we are possessing norms and structures that inhibit change.

In order to delve deeper into the phenomenon and to investigate the teachers' experiences, we summarized our ethnographic data collected through participant observation. The ways teachers gave impressions on practice varied 
strongly. Some participants used short notes, some only bullet points for weekly descriptions. Others were writing a diary, with long sentenced portraiture of daily school life with detailed descriptions of their feelings and emotions. This enhanced our study, as the "highs and lows" of acculturative stress and the progress over time, can only be explained with spoken and written reflections from teachers. Natural rationalization for the phenomenon is aspiration to explain the long-term course and causes of stress and adaptation and describe different acculturation experiences (Demes \& Geeraert, 2015). Figure 5 explains the thoughts and feelings teachers had at different culmination points of the study. These are direct quotations from teacher reflection sheets and shared discussions.

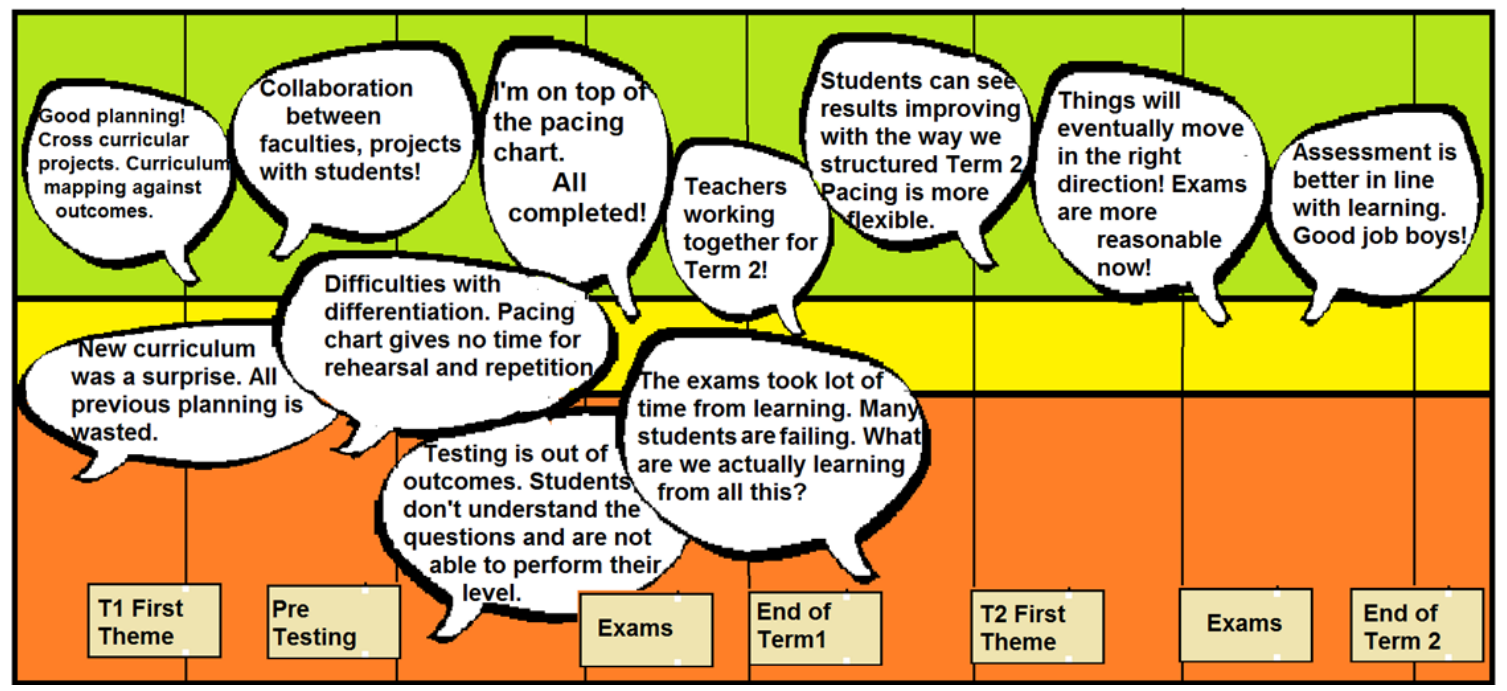

Figure 5. Discussion in culmination points

The final findings are based on the dimensions of our reflection template. We have strung together the core message from each point of view: student, teacher and community. According to the data gathered from teachers' reflections, shared discussions, and field notes the following summary statements emerged:

From the student point of view, the most important indicator was the relationship and connection between teacher and the learners. What the new curriculum brought to this connection is a pacing chart for teachers to follow giving consistency across the UAE. Many teachers felt at the beginning that the standardized pacing hindered differentiation, making it difficult to adjust teaching for student's needs. It is crucial for students to acquire new knowledge at an appropriate pace. Individual learning paths are modified through differentiation, and most teachers in the study felt inadequate in this area. External testing gave good accountable data about the learning results and progress, but teachers believed the level of exams was too difficult for some students and took lots of time away from valuable teaching. During the first term, teacher confidence split during the testing period significantly. 
Teacher point of view for planning followed the previous statement. Standardized new curriculum and pacing charts surprised teachers when they returning at the beginning of the school year. Some teachers had planned carefully for the new school year before leaving for summer break. The unpredictable change left them shocked and feeling they had wasted their time. The new curriculum has a spiraling delivery model for learning, allowing students to study learning outcomes more than once during the term. This was perceived as a good modification from the old system, but the pacing chart was hindering the usage of this model against the real pace of learning for students. During the second period of observation, the teachers found ways to differentiate the teaching and classroom routines more effectively despite the pacing charts and became more comfortable with the new curricula.

Teaching communities went through a period of cultural change, strongly connected to work satisfaction especially during the first term and testing weeks. The model was new for everyone, and different for Arabic and English teachers causing lots of stress among teachers. In some schools, this difference led to division of the two faculties. The situation clearly improved during the second half of the observations and teachers' adapted ways to plan together. However, cross-curricular planning remained difficult because of the different curricular conditions.

These results of the study are not to be taken account without a notice of limitations. The limitations of this case study are characteristics for design of ethnographic study. This study is an active field study with a particular setting observed. The results can only be applicable for this single setting. We are analyzing subjective information and therefore, the results are only valid concerning the study group and the Pilot schools. We realize the study group is rather small, and the idea is more to reflect deeply the situation than to generalize. The internal validity is strong with the method of ethnography, but the external validity could only be confirmed by comparing these findings to other similar studies.

\section{Analysis of Findings}

Using an ethnographic lens, the most significant component of defining grounded theory would probably be accurate "theoretical sampling". System data is collected and evidence for emerging theory is documented and allocated. This consisted of teacher reflections and field notes for analyses, as well as our own observations and notes supported by theoretical background from previous research.

Ethnographers need to be able to create a sense of immediacy for their study group, not only to their writings but also toward the culture they are describing. Our study group enabled teachers to reflect on the reality in their classrooms. These reflections are subjective in nature. Ethnographic researchers need to 
recognize that their interpretations are to be as subjective and stylistically embedded in the rhetoric of the study as the teacher reflections.

For this reason, we used the method of configurational validity to the arrangement of elements from the reflections to reveal the underlying themes of school culture and to discern shared patterns for further discussion. Chart 4 brought together the final form of the elements of teacher reflections, after selection, allocation and Interfacing of components. (e.g. Eisner, 1992; Goldman, 2007)

\section{Chart 4: Elements of teacher reflections}

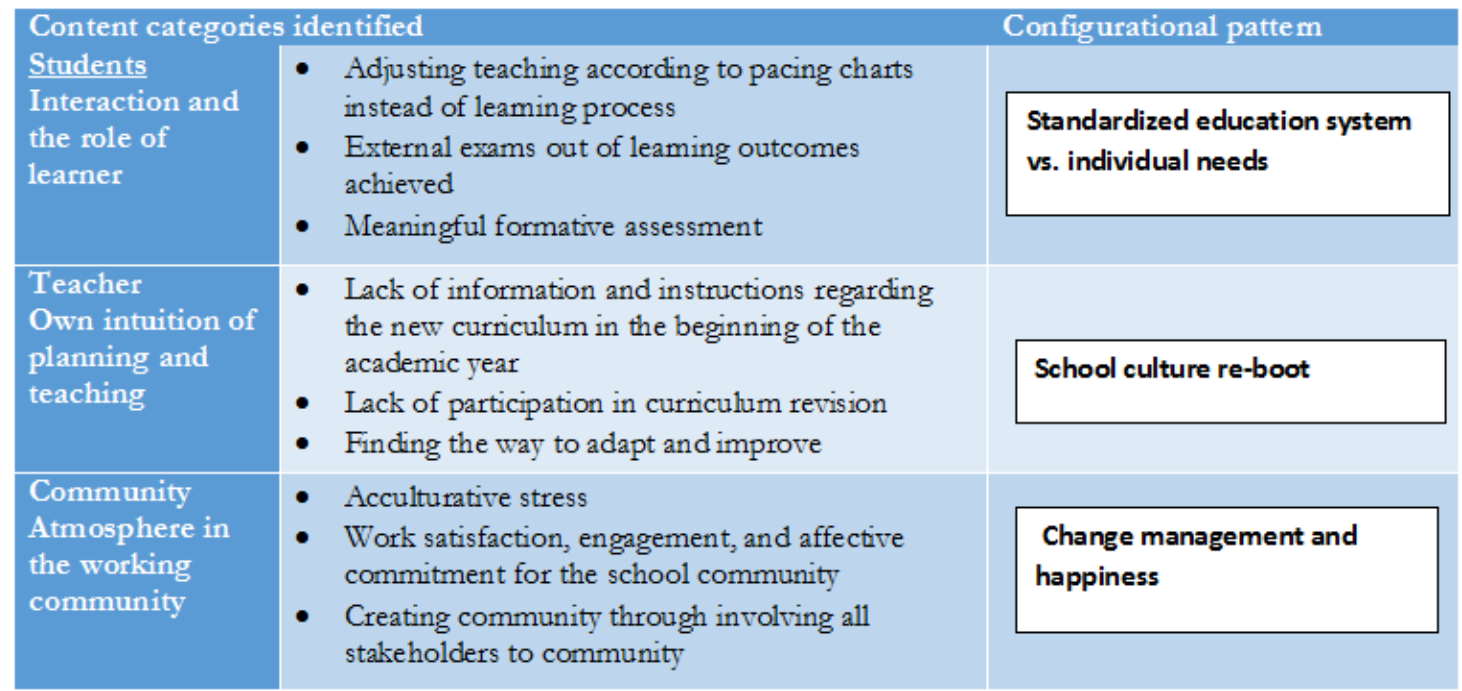

After data collection, we evaluated the collected data in comparison to the theoretical floor for content categories. The content category describes the actual concepts of school world and shows the elements of school culture. Further analysis revealed the configurational patterns, which are considered change force, or key concept for positive school culture and further improvement in the whole school. Adaptation to current curricular conditions in Abu Dhabi seems to build on three concepts: the question between standardization and individualization, re-boosting the school culture to get over the changes made by the new curriculum and change management as well as happiness in schools. Using these realizations, we can yield for theoretical discussion to understand the phenomena at a deeper level.

\section{Discussion}

The study reveals that school administrators can manipulate school culture, including the learning environment for the students and work place for teachers by first providing standardized system for teaching and assessment and sufficient resources in a suitable learning environment for the students. If we follow the scientific discussion regarding school standards, countries that underperformed in international school evaluations tests like PISA, TIMMS and PIRLS in the last few years are reevaluating their systems and moving to more 
standardized school systems and centralized testing to achieve higher scores internationally (Sleeter \& Carmona, 2016).

To achieve higher standards of learning, educators must understand students accomplish standards in their own timeframe. Students who learn the standard faster than others cannot be held back from proceeding to the next level because that would be lowering the standards for those students. On the other hand, students who are falling behind need more time and support to reach the same achievements. At the same time, we must not forget the importance of motivation, especially as regards the acquisition of second language learners (Heinz, 2017).

The international movement towards more standardized school systems has also evoked people involved to use caution when discussing school standards. There are concerned voices about the basic idea of standardization. Unfortunately, most of the discussions about standards theoretically centers on the importance of standards. Not much research on what they should be, and even less thought given to the consequences of their implementation. Proper implementation of high standard is a necessity to improve the quality of teaching, but if this implementation is not done well, standards can do far more harm than good. Standardization allows for accountability in teaching and assessment ${ }^{3}$ but does not necessarily lead to improvement of learning (Reigeluth, 1997; Sleeter \& Carmona, 2016).

An understanding that standards can be utilized in two very different ways representing very different views of education is essential. They can be used as tools for standardization itself, to help make the education for all students similarly measurable. Alternatively, they can be used as tools for customization, helping meet individual students' needs.

Striving for excellence to maximize the achievement attained by each studentis the most appropriate of school goals and the one all stakeholders can agree on. This kind of excellence is best promoted when standards are flexible, fitted individually, in other words, customized. We need customization instead of standardization, focusing on learning (attaining high standards) rather than on organization (Watson \& Watson, 2007.)

For a customized educational system focus on learning, a high level of specification helps teachers generate resources, and assists them in keeping track of student attainments, with technology to manage the diversity. Standards must be challenging yet attainable to students who differ in ability. What can be done to achieve this endeavor? Teachers must determine what standards are

\footnotetext{
${ }^{3}$ Standardized testing and high-stakes testing are common examples that lead to what is called "teaching to the test". Policies in most countries require standardized testing at certain grade levels, putting pressure on teachers to ensure student performance is at a high level on these tests. Teachers do this by teaching specific content found on the tests and coaching students on test-taking skills. These actions of course are not in benefit of the student in a long run.
} 
appropriate for a child based on the child's development stage. The main limitations should be that there are certain attainments valued by the community or government, sometimes called mandatory basic skills (minimum standards), which must be attempted and pursued in the classroom. Deciding on standards and time should be the teachers' choice to a certain degree with an understanding of what is mandatory allowing teachers to be focused on learning. Teachers must also provide the instructional processes for students to attain the standard goals (Sleeter \& Carmona, 2016).

Weinstein (1996) stated, "Without appropriate pedagogy as well as systemic support, tough standards and punitive accountability will hold children and teachers accountable without providing the means to successfully meet those standards" (p.18). The teacher's role must change from directing the class to the role of mentor or coach to make significant change. This study shows teachers need to be treated as professionals and given certain autonomy, to self-evaluate the procedures in the classroom, make judgements and decisions to benefit learning. The two most important conditions for active mental engagement are motivation to learn at a maximum level and quality instructional support. Common, uniform standards can be counterproductive to these conditions. We need standards for customization instead of standardization in education to accelerate the learning process (Watson \& Watson, 2007; Sleeter \& Carmona, 2016).

One path for customization is to cherish positive and unique school culture. School culture is a combination of teacher/student relationships, teacher/student engagement and individual ownership to school community. If there are means for school administrators to manipulate the standards driving student attainment, there are means to develop school culture. Like culture everywhere, a school culture generates from both conscious and unconscious elements, values, interactions, and practices, and it is strongly built on school's particular institutional history. Students, parents, teachers, administrators, and other staff members all contribute to the culture of the school, as do external effects such as location, administrative policies that govern how it operates, and the ideological principles upon which the education is founded. Culture is a result of human actions; this means that culture emerges from the life of the community through thoughts shared and voices heard (Msila, 2014.)

The foundation for positive school culture must be collaboration of all stakeholders in important management decisions pertaining to the learning community. On the verge of major changes, a cultural re-boot is necessary, and every members' input is needed (Kaplan \& Owings, 2013).

Positive school culture emulates happiness. The concept of happiness shows in school culture when there is work satisfaction, pleasant learning conditions, active learning community and processes in place to succeed. Happiness at school is like an umbrella covering both internal and external conditions, which affect the moods and atmosphere among people. Research evidence shows that happiness-related factors have important consequences for both individuals and 
organizations. Happiness in school on the group and personal levels is related to core and contextual performance, student satisfaction, safety, attendance, and retention. The strongest relationships happen when both happiness and outcomes are hypothesized and measured broadly (Fisher 2010).

Markku Ojanen (2001) is a happiness researcher who outlines all things that are constantly inspiring and seemingly interesting will raise happiness. When we do good and positive things for other people, the joy of giving rewards us. The basic condition for happiness is when there is no confrontation but an aura of supporting each other. We do not compete, but we work together for better community and at the same time for better individual conditions. These factors and recent research on actions taken to improve happiness show why improving happiness is a worthwhile goal. Evidence suggests when someone is happy his or her productivity increases (Roehling, Cavanaugh, Moynihan, \& Boswell, 2000). Therefore, employer-employee relationships must rely on both parties being satisfied with the situation and work at meeting each other's' expectations. Happiness at work is the glue that retains and motivates quality employees to remain.

\section{Conclusion}

The focus of this pilot project has been evaluating curriculum delivery and investigating teachers' satisfaction on the curriculum reform process. At the center of the entire process has been strong engagement between school administration and teachers. We have identified the importance of external and internal norms, as well as expectations for effective curriculum delivery (Eranpalo et al., 2016), and the key roles teachers take to achieve cross-curricular learning conditions for students through collaboration (Jorgenson et al., 2017). We also discovered the importance of teacher autonomy in curriculum delivery to improve student motivation and engagement (Valanne, Al Dhaheri, Kylmalahti \& Sandholm-Rangell, 2017).

This study is the final contribution for the Pilot coming full-circle to identify the same problematic. More closely, it is about adapting to specific curricular conditions and developing ways to deliver curriculum, which affect the school culture in Abu Dhabi. The period of curriculum reform can be described as a transformative experience for the teachers and students, but also for other stakeholders in school communities.

Transformation in a process happens when there are adequate forces to bring about the change. Sometimes a robust atmosphere like the notion of re-birth is needed. There are always some elements of discomfort or pain involved in transformational change because our mindset and existing assumptions, habits and behaviors are challenged. We have to give up something old to accept the new. This is the case also with MoE curriculum reform in UAE. We cannot achieve new educational structures without giving up old ones. 
Transformation is not intended to be a one-time experience. It may happen throughout the course of a long period. It is a progressive upward spiral with each cycle beginning with an event that may cause turmoil and conflict within oneself or the whole organization. It can give us a sense of disorientation or feeling of loss, making us search for the reasons why by questioning and reflecting deeply on the experience. Analyzing these changes leads to a heightened awareness and an understanding that existing practices limit progress. To go through transformation, everyone must be open to risks and willing to explore the unknown to gain a new understanding. The next cycle of transformation would begin with an event triggering the need for change (Scherto, 2007). To succeed in a major curriculum reform, critical reflection, analysis and development of a new understanding must take place for the 'Universal design'.

If we follow the reasoning of Rose and Meyer (2006), who developed the notion of so-called 'Universal Design' for Learning in the 1990s, we can understand that new curriculum and designing curriculum is something that should be done patiently and in caution with time, in a continuous dialogue with all stakeholders.

Universal Design for Learning requires teachers develop short-term plans reflecting the current success of students. All learners are important in this design since decisions are made based on gathering facts and developing instruction based on individual requirements and interests as the teacher parallels on changes needed for curriculum. Thousand, Villa \& Nevin (2007) called this designing "retrofitting". Retrofitting refers to actions when you add innovations or features to old or existing systems. Retrofitting means you take old, existing system and accommodate it with current conditions. In school, retrofitting is planning based on existing standards and content, the processes of measurable outcomes or mastery. This kind of approach is only possible when teachers are planning the curriculum in collaboration, reflecting on the effect of actions for students. The conditions and results of these processes vary with differences in schools.

Actually, it may be that the universal design for learning is really 'individual design' for learning. In order for school culture to change, power must be given to allow all involved to gain a sense of ownership to the process of change (Hinde, 2018). At the same time, if change evolves fast enough that stakeholder's miss adapting to the change, the results can be modest. Through the analysis of our research, we noticed a descending ethos, especially in the beginning of the research. The curriculum change was large-scale and high-speed, which left schools facing high level of challenge. Liddicoat et al., (2017) maintain for school to work through change or innovation, reflection needs to focus on change implementation and conditions associated with the change. The development of a strong, positive culture increases the scope, depth, complexity, and success teachers and students achieve. Sometimes culture can hinder transformation when values are conflicting with the advancement of the school's goals and effectiveness. This happens most of the time when an organization is trying to 
change too rapidly (Kaplan \& Owings, 2013; López-Pérez \& Fernández-Castilla, 2017).

For educators to provide individual school plans for every student, what we have learned means customization instead of standardization. Education has only scratched the surface on customizing learner experiences. The need to find individual learning paths for students is based upon several background assumptions about nature and present state of education. Equity in education does not mean only equal access and inputs. Teachers must work to ensure that all components are personalized; students educational plans, curriculum, instruction, and schedule to meet the student's needs. Customized learning requires a different approach to curriculum design and delivery, different assumptions for reaching the standards. The premise of the theory rests on the belief students make larger gains when they take part in the planning of their education. Even though this concept makes a lot of sense there is not much research about it.

This pilot has been a three-year project of investigation into curriculum delivery in Abu Dhabi. We hope that in the future schools and educators will find ways to utilize our findings. We are also thankful for all stakeholders who participate in this project.

\section{References}

Ball, D. L., \& Cohen, D. K. (1996). Reform by the book: What is - or might be - the role of curriculum materials in teacher learning and instructional reform? Educational Researcher, 25(9), 6-8. doi: https://doi.org/10.2307/1177151.

Berry J. W. (1997). Immigration, acculturation, and adaptation. Applied Psychology, 46, 5, 68. doi: https://doi.org/10.1111/j.1464-0597.1997.tb01087.x

Berry J. W. (2006). Stress perspectives on acculturation In Sam D. L. \& Berry J. W. (Eds.), The Cambridge handbook of acculturation psychology,43-57. doi: https://doi.org/10.1017/cbo9780511489891.007.

Bjerrun Nielsen, H. (1995). Seductive texts with serious intentions. Educational Researcher, 24 (1), 4-12. doi: https://doi.org/10.3102/0013189x024001004.

Bolger, N., \& Zuckerman, A. (1995). A framework for studying personality in the stress process. Journal of Personality and Social Psychology, 69, 890-902. doi: https://doi.org/10.1037//0022-3514.69.5.890.

Brickman, P., \& Campbell, D. T. (1971). Hedonic relativism and planning the good society. In M. H.Appley (Ed.), Adaptation level theory: A symposium (pp. 287302). New York: Academic Press.

Butucha, Q. (2013). Gender and School type Differences in Self-efficacy inTeaching. Sky Journal of Education Research 1(14), 23-31.

Carver, C.S.\&Connor-Smith J. (2010). Personality and coping. Annual Review of Psychology 61, 679-704.

Church A. T. (1982). Sojourner adjustment. Psychological Bulletin, 91, 540-572. doi: https://doi.org/10.1037//0033-2909.91.3.540. 
Davis, E. A., \& Krajcik, J. S. (2005). Designing educative curriculum materials to promote teacher learning. Educational Researcher, 34(3), 3-14.

doi:https://doi.org/10.3102/0013189x034003003.

Demes, K. A., \& Geeraert, N. (2015). The highs and lows of studying abroad: A longitudinal analysis of sojourner stress and adaptation in 50 countries. Journal of Personality and Social Psychology, 109, 316-337. doi: https://doi.org/10.1037/pspp0000046.

Diener E., Lucas R. E., \& Scollon C. N. (2006). Beyond the hedonic treadmill: Revising the adaptation theory of well-being. American Psychologist.61:305-314. doi: https://doi.org/10.1007/978-90-481-2350-6_5.

Diener, E., \& Seligman, M. E. (2004). Beyond money: Toward an economy of wellbeing. Psychological Science in the Public Interest, 5, 1-31. doi: https://doi.org/10.1111/j.0963-7214.2004.00501001.x.

Dujardin, A-F. (2013). Adapting ethnographic action research to study responses to educational technology. In: LCSS PhD Conference 2013: Methodological Choices and Challenges, King's College, London, 19 April 2013.

Drake, C. \& Sherin, M. (2006). Practicing change: Curriculum adaptation and teacher narrative in the context of mathematics education reform. Curriculum Inquiry 36, (2), 153-187. doi: https:// doi.org/10.1111/j.1467-873x.2006.00351.x

Eisner, E. (1992). The enlightened eye: Qualitative inquiry and the enhancement of educational practice. New York: McMillian Publishing Company.

Eranpalo, T., Jorgenson C. K. \& Woolsey, M. L. (2016). The Abu Dhabi school model: Effective delivery of the curriculum. International Journal of Humanities and Social Sciences Vol 8, No 6.

Eysenck, M. W. (1990). Happiness: Facts and myths. London: Lawrence Erlbaum.

Fisher, C. D., (2010). Happiness at work. International journal of management reviews, 12 (4), 384-412. doi: https:// doi.org/10.1111/j.1468-2370.2009.00270.x.

Foth, M. (2006). Sociocultural animation. In: Marshall, S., Taylor, W. \& Yu, X. (Eds.) Encyclopedia of Developing Regional Communities with Information and Communication Technology. Hershey, PA: Idea Group Reference. pp. 640-645. doi: https://doi.org/10.4018/9781591405757.ch114.

Geeraert N., \& Demoulin S. (2013). Acculturative stress or resilience? A longitudinal multilevel analysis of sojourners' stress and self- esteem. Journal of Cross-Cultural Psychology, 44, 1239-1260. doi: https://doi.org/10.1177/0022022113478656.

Godfrey, D (2014). Leadership of schools as research-led organizations in the English educational environment-Cultivating a research-engaged school culture. Educational Management Administration \& Leadership, 44 (2), 301- 321. doi: https://doi.org/10.1177/1741143213508294.

Goldman, R. (2007). Video representations and the perspectivity framework: epistemology, ethnography, evaluation, and ethics. In R. Goldman, R. D. Pea, B. Barron, \& S. Derry, (Eds.), Video research in the learning sciences. Mahwah, NJ: LEA. doi: https://doi.org/10.4324/9780203877258.

Goldman-Segal, R. (1995). Configurational validity: A proposal for analyzing multimedia ethnographic narratives. Journal for Educational Multimedia and Hypermedia, 4(2), 163-182.

Goldman-Segall, R. (1998). Points of viewing children's thinking: A digital ethnographer's journey. Mahwah, NJ: Lawrence Erlbaum Associates. doi: https://doi.org/10.2307/1585784. 
Gross, J. J. \& John, O. P. (2003). Individual differences in two emotion regulation processes: Implications for affect, relationships, and well-being. Journal of Personality and Social Psychology, 85, 348-362. doi: https://doi.org/10.1037/00223514.85.2.348.

Gruenert, S., \& Whitaker, T. (2015). School culture rewired: How to define, assess and transform it. Alexandria, VA: Association for Supervisors of Curriculum Development.

Hargreaves, A. (1997). Rethinking educational change with heart and mind: 1997 ASCD yearbook. Virginia: Association for Supervision and Curriculum Development. In Hinde, E. R. School Culture and Change: An Examination of the Effects of School Culture on the Process of Change. doi: https://doi.org/10.2307/1585989.

Heracleous, L. (2001). An ethnographic study of culture in the context of organizational change. The Journal of Applied Behavioral Science, 37 (4), pp. 426-446. doi: https://doi.org/10.1177/0021886301374003.

Herman J. L., \&Tetrick L. E. (2009). Problem-focused versus emotion-focused coping strategies and repatriation adjustment. Human Resource Management, 48, 69-88. doi: https://doi.org/10.1002/hrm.20267.

Hearn, G. N., Tacchi, J. A., Foth, M. \& Lennie, J. (2009) Action Research and New Media: Concepts, Methods and Cases. New York: Hampton press.

Heinz, M. (2017) Korean University Students" Perceptions of Teacher Motivational Strategies. International Journal of Learning, Teaching and Educational Research, 16 (9): 29-41. doi:https://doi.org/10.26803/ijlter.16.9.3.

Hinde, E. R. (2018). School Culture and Change: An Examination of the Effects of School Culture on the Process of Change. International Journal of Educational Reform, 21(1), 35-46.

Johnson, J. A. (2018). Principles of Effective Change: Curriculum Revision That Works. The Journal of Research for Educational Leaders, 1(1), 5-18. https://www2.education.uiowa.edu/archives/jrel/fall01/Johnson_0101.

Jorgenson, C. A., Eranpalo, T., Deria, A.M. \& Kumar R. (2017). Using Abu Dhabi Education Council's Abu Dhabi School Model Outcomes to Reorganize Curriculum from Linear Delivery toward a Spiral Approach. International Journal of Humanities and Social Sciences , 9 (3).

Kaplan L. S. \& Owings, W. A. (2013). School Culture and Change as Learning. InCulture Re-Boot: Reinvigorating School Culture to Improve Student Outcomes. Sage Knowledge. doi :https://uk.sagepub.com/sites/default/files/upmbinaries/53502_Kaplan_c hapter_1.pdf.

Liddicoat, A., Scarino, A. \& Kohler, M. (2017). The impact of school structures and cultures on change in teaching and learning: the case of languages. Curriculum Perspectives, 38(1), 3-13. doi: https:// doi.org/10.1007/s41297-017-0021-y

López-Pérez, B \&Fernández-Castilla, B. (2017). Children's and adolescents' conceptions of happiness at school and its relation with their own happiness and their academic performance. Journal of Happiness Studies,1, 1-20. doi: https://doi.org/10.1007/s10902-017-9895-5.

Lysgaard S. (1955). Adjustment in a foreign society: Norwegian Fullbright grantees visiting the United States. International Social Science Bulletin, 7, 45-51.

Macneil, A, J., Prater, D. L. \& Busch S. (2009). The effects of school culture and climate on student achievement. International Journal Leadership in Education, 12 (1), pp. 73-84. 
Ministry of Education, UAE (2018). Retrieved from

https://www.moe.gov.ae/En/Pages/Home.aspx

Msila, V.(2014). Manipulating school culture for effective leadership. Mediterranean Journal of Social Sciences. Rome, Italy: MCSER Publishing. doi: https:// doi.org/10.5901/mjss.2014.v5n23p1276.

Oberg K. (1960). Cultural shock: Adjustment to new cultural environments. Practical Anthropology, 7, 177-182. doi: https://doi.org/10.1177/009182966000700405

Ojanen, M. (2001). Ilo, onni ja hyvinvointi. Helsinki: Kirjapaja.

Penley J. A., \& Tomaka J. (2002). Associations among the Big Five, emotional responses, and coping with acute stress. Personality and Individual Differences, 32, 1215-1228. doi: https://doi.org/10.1016/s0191-8869(01)00087-3.

Reigeluth, C. M. (1997). Educational standards: To standardize or to customize learning? Phi Delta Kappan, 79(3), 202-206.

Remillard, J. T., \& Bryans, M. B. (2004). Teachers' orientations toward mathematics curriculum materials: Implications for teacher learning. Journal for Research in Mathematics Education, 35(5), 352-388. doi: https://doi.org/10.2307/30034820.

Roehling, M.V., Cavanaugh, M.A., Moynihan, L.M. and Boswell, W.R. (2000). The nature of the new employment relationship: A content analysis of the practitioner and academic literatures. Human Resource Management, 39, 305-320. doi: https://doi.org/10.1002/1099-050x(200024)39:4<305::aid hrm3>3.0.co;2-v.

Rose, D. \& Meyer, A.(2006). A practical reader in universal design for learning. Cambridge, MA: Harvard Education Press.

Rosenholtz, S. (1989). Teachers' workplace: The social organization of schools. New York: Longman.

Sahlberg, P. (2012). Quality and equality Finnish Schools. School Administrator, 9. https:// pasisahlberg.com/wp content/uploads/2013/01/Qualit_and_Equity_SA_2012.pdf.

Schein, E.H. (1985). Organizational culture and leadership. San Francisco: Jossey Bass.

Scherto, G. (2007). Rethinking educational change: Transformation througheducation. Based on the proceedings of the Third Vittachi International Conference July 2006. Conceptualizing Transformation and Its Application in Education (p. 19-25). Brighton. UK: Guerrand-Hermès Foundation for Peace.

http://ghfp.org/Portals/ghfp/documents/Education_As_Transfomation_Book _Fnal.pdf.

Schwartz, S.J., Unger, J.B., Zamboanga, B.L. \&Szapocznik, J. (2010). Rethinking the concept of acculturation: implications for theory and research. American Psychologist, 65(4), 237-51. doi: https://doi.org/10.1037/a0019330.

Sleeter, C., \& Carmona, J. F. (2006). Un-standardizing curriculum: Multiculturalteaching in the standards-based classroom. New York, NY: Teachers College Press. doi: https://doi.org/10.5860/choice.43-5413.

Spradley, J. (2016). Participant Observation. Chicago: Waveland Press.

Staudinger, U. M., \&Fleeson, W. (1996). Self and personality in old and very old age: Asample case of resilience? Development and Psychopathology, 8, 867-885. doi: https:// doi.org/10.1017/s0954579400007471.

Stoll, L (1998). School Culture. School Improvement Network's Bulletin, No. 9,Institute of Education. University of London.

Stoll, L., \& Fink, D. (1996). Changing our schools: Linking school effectiveness and school improvement. Buckingham: Open University Press.

Tacchi, J., Foth, M. \& Hearn, G. (2009). Action research practices and media fordevelopment. International Journal of Education and Development using ICT, 5 (2), 32-48. 
Tacchi, J., Slater, D. \& Hearn, G. (2003). Ethnographic Action Research: A User's Handbook Developed. New Delhi: UNESCO. doi: https://doi.org/10.4135/9781473921290.n22.

Thousand, J. S., Villa, R. A., \& Nevin, A. I. (2007). Differentiating instruction: Collaborative planning and teaching for universally designed learning. Thousand Oaks, CA: Corwin Press.

Valanne, E., Al Dhaheri, R., Kylmalahti, R. \& Sandholm-Rangell, H. (2017). Phenomenon-based Learning Implemented in Abu Dhabi School Model. International Journal of Humanities and Social Sciences, Vol 9, No 3.

Ward C., Leong C.-H., \& Low M. (2004). Personality and sojourner adjustment: An exploration of the Big Five and the Cultural Fit proposition. Journal of Cross Cultural Psychology, 35, 137-151. doi: https://doi.org/10.1177/0022022103260719.

Watson, W. R., \& Watson, S. L. (2007). An argument for clarity: What are learning management systems, what are they not, and what should they become? TechTrends, 51(2), 28-34. doi: https://doi.org/10.1007/s11528-007-0023-y.

Weinstein, R. S. (1996). High standards in a tracked system of schooling: For which students and with what educational supports? Educational Researcher, 25 (8), 1619. doi: https://doi.org/10.2307/1176485. 